\title{
Consumo de água e energia em canteiros de obra: um estudo de caso do diagnóstico a ações visando à sustentabilidade
}

\author{
Water and energy consumption in construction sites: $a$ \\ case study from diagnosis to actions aiming at \\ sustainability
}

\section{Cristian Teixeira Marques \\ Bárbara Maria Fritzen Gomes Luciana Londero Brandli}

\section{Resumo

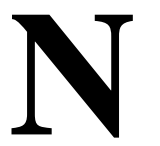

o contexto do desenvolvimento sustentável, a indústria da construção civil enfrenta desafios, entre eles a busca por maiores níveis de qualidade e eficiência em seus processos produtivos e no consumo dos recursos naturais. Este artigo tem o objetivo de apresentar uma análise do consumo de energia e de água durante a fase construtiva das edificações, demonstrando medidas que podem ser adotadas no processo de produção a fim de reduzir o consumo dos referidos insumos e melhorar o desempenho dos processos em uma construtora. A pesquisa foi realizada em seis obras de uma construtora na cidade de Passo Fundo, RS, mediante o monitoramento dos consumos mensais ao longo de 5 anos. Como resultados são propostas ações econômicas, tecnológicas e sociais para melhorias nesses indicadores. Os resultados demonstram que são necessários o monitoramento e a gestão contínua do consumo de água e energia dentro dos canteiros de obra. Entre as ações sugeridas destaca-se o comprometimento da direção da empresa com a eficiência no uso dos recursos na obra.

Palavras-chave: Consumo de energia. Consumo de água. Indicadores. Canteiro de obra.

\section{Abstract}

Sustainable development presents a number of challenges for the construction industry. Among them are reaching higher levels of quality and efficiency in its production processes and the consumption of natural resources. The aim of this paper is to present an analysis of the energy and water consumption during the construction phase of buildings, showing measures that can be adopted in the production process in order to reduce resources and improve the process performance. This research was carried out in six construction sites in the city of Passo Fundo-RS, monitoring the monthly consumptions over 5 years. As results, economic, technological and social actions are proposed to improve these indicators. The results show that continuous monitoring and management of water and energy consumption in the construction sites is necessary. Suggested actions include commitment from the company's management to efficiently use the resources in the construction sites.

Recebido em 31/03/17 Aceito em 10/08/17
Keywords: Energy consumption. Water consumption. Indicators. Construction site. 


\section{Introdução}

No atual panorama do desenvolvimento sustentável (UNITED..., 2015), as discussões permeiam o comprometimento das nações e da sociedade científica em prol do alcance dos objetivos do desenvolvimento sustentável (ODS) lançados pela ONU e acordados por 193 paísesmembros em 2015 (ORGANIZAÇÃO..., 2016). A indústria da construção civil está entre os setoresalvo dessa agenda global de sustentabilidade (AJAYI et al., 2017). Várias metas podem ser relacionadas à construção civil e podem ser encontradas nos diferentes objetivos do desenvolvimento sustentável: ODS 6 - assegurar a disponibilidade e gestão sustentável da água e saneamento para todas e todos; ODS 9 - construir infraestruturas resilientes, promover a industrialização inclusiva e sustentável e fomentar a inovação; ODS 11 - tornar as cidades e os assentamentos humanos inclusivos, seguros, resilientes e sustentáveis; e ODS 12 - assegurar padrões de produção e de consumo sustentáveis (LOPES; OLIVEIRA; ABREU, 2017; SOBOTKA; SAGAN, 2016). Na perspectiva de contribuir para essa agenda, especialmente no que se refere ao padrão de produção sustentável, este artigo focaliza a gestão de recursos ambientais na fase construtiva das edificações.

A sustentabilidade deve estar presente em todas as etapas do ciclo de vida de um empreendimento, desde sua concepção, projeto, construção e manutenção até sua demolição, considerando sempre as três dimensões da sustentabilidade: econômica, social e ambiental (ARAÚJO, 2009). A etapa de construção, no ciclo de vida de um empreendimento, responde por uma parcela significativa dos impactos causados pela construção civil no meio ambiente (CARDOSO; ARAÚJO, 2006).

O canteiro de obra é o ambiente onde é realizada a principal atividade da construção civil, além de ser o momento e local de maior interação entre a maioria dos elementos da cadeia produtiva, incorrendo em importantes impactos ambientais e sociais. Na prática, o canteiro de obra deve ser um processo dinâmico e adaptável, ambiente propício para a aplicação de ações de melhorias, uma vez que nele estão envolvidos os principais recursos financeiros e humanos (SOUZA, 2000).

Tavares (2007) e Agopyan et al. (1998) salientam que no Brasil, até o início da década de 1990, as questões ambientais não recebiam a devida relevância e que apenas após esse período surgiram estudos sistemáticos e resultados mensuráveis sobre reciclagem, redução de perdas e de energia na indústria da construção. Também contextualizando a construção civil, Salgado, Chatelet e Fernandez (2012) afirmam que a discussão a respeito do projeto e execução de edificações sustentáveis vem sendo abordada por diferentes autores, em geral com foco no desempenho da edificação e na vida útil dos materiais que a compõem.

Cardoso e Araújo (2006) comentam que as interferências causadas pelos canteiros de obra não têm merecido a devida atenção das empresas e dos profissionais e acadêmicos, embora também causem impactos significativos, como incômodos à vizinhança (sonoros, visuais, etc.) e poluição (ao solo, à água e ao ar), impactos ao local da obra (ecossistemas, erosões, assoreamentos, trânsito, entre outros aspectos) e consumo de recursos (principalmente água e energia). Além disso, de acordo com Sharrard, Matthews e Roth (2007), a maioria das pesquisas prioriza impactos da construção civil apenas na seleção de material e na fase de operação de edificações.

Durante a execução de uma obra se verifica boa parte dos impactos causados pela construção civil, o que justifica a necessidade de se conhecerem as intensidades desses impactos, pois, uma vez priorizados, podem ser reduzidos ou eliminados por meio de ações específicas (CARDOSO; ARAÚJO, 2004; MACHADO, 2006). Alguns estudos abordam medidas mitigadoras para a fase construtiva das edificações (AGOPYAN et al., 1998; SOBOTKA; SAGAN, 2016), porém consideram apenas a gestão de resíduos sólidos da construção civil. Não obstante, os desafios para o setor da construção são diversos, devendo, entre outros, buscar soluções que potencializem o uso racional de energia e de outras energias renováveis e a gestão ecológica da água (MINISTÉRIO..., 2017).

Diante desse contexto, o objetivo deste artigo é apresentar uma análise do consumo de energia e de água durante a fase construtiva das edificações, demonstrando medidas que podem ser adotadas no processo de produção a fim de reduzir o consumo dos referidos insumos e de melhorar o desempenho dos processos em uma construtora. Busca-se, a partir deste estudo de caso, aprofundar as discussões acerca do consumo de energia e água na fase construtiva das edificações e fornecer subsídios para que outras empresas possam gerenciar de forma mais sustentável o uso desses recursos. 


\section{Sustentabilidade no uso de energia e água em canteiros de obra}

Na perspectiva das empresas de construção civil, Dias (2006) salienta a necessidade de se buscarem maiores níveis de qualidade e eficiência nos processos por meio da racionalização da produção. Para que o processo de construção sustentável atinja os objetivos do desenvolvimento sustentável, Farias (2010) recomenda a implementação de métodos e ações passivas, processos construtivos rigorosos e detalhados, seleção e utilização de materiais mais ecológicos e também avaliação e monitoramento contínuos.

Pode-se dizer que alguns dos princípios básicos a serem implementados para uma construção sustentável consistem em ações de redução e otimização do consumo de materiais e energia, redução dos resíduos gerados, redução do consumo de água, aproveitamento das condições naturais locais, preservação do ambiente natural e melhoria da qualidade do ambiente construído (SINDICATO..., 2016).

Oliveira e Gonçalves (1999) sugerem que as ações visando à evolução de práticas e conscientização sobre desenvolvimento sustentável na construção civil sejam estruturadas de acordo com aspectos tecnológicos, econômicos e sociais. Os autores afirmam que essa estrutura de categorização das ações pode ser utilizada para o consumo de água e o consumo de energia elétrica. A exemplo das ações tecnológicas, estas estariam relacionadas à substituição de sistemas e aos componentes com melhor ecoeficiência; as ações econômicas envolveriam subsídios externos como redução de tarifas para usos de sistemas e componentes economizadores; e as ações sociais estariam focadas na conscientização e na educação ambiental do uso dos recursos (Figura 1).

Quanto ao consumo de energia elétrica, o setor da construção civil utiliza a energia de forma pouco eficiente, existindo um potencial elevado para sua redução. No entanto, o setor ainda enfrenta um grande desafio ao tentar aumentar a eficiência energética durante e após a execução da obra, pois é responsável por uma das maiores demandas energéticas do mundo (BALTAR; KAEHLER; PEREIRA, 2006). Crawford e Treolar (2005) afirmam que a energia operacional tem sido objeto de muitas pesquisas quanto à conservação e eficiência, incluindo usos para aquecimento, resfriamento, ventilação, iluminação, transporte vertical e outras formas de consumo. A maior parte de pesquisas concentra-se em avaliações de impactos energéticos da construção civil, quanto ao ciclo de vida de matérias-primas e serviços, e na fase de operação e uso de edificações, considerando na fase de execução apenas avaliações de consumo de energia relacionada a combustíveis e emissões de dióxido de carbono (CARDOSO; ARAÚJO, 2006; SHARRARD; MATTHEWS; ROTH, 2007; CRAWFORD; TREOLAR, 2005).

Figura 1 - Classificação das ações que interferem no consumo de água e energia em canteiros de obra

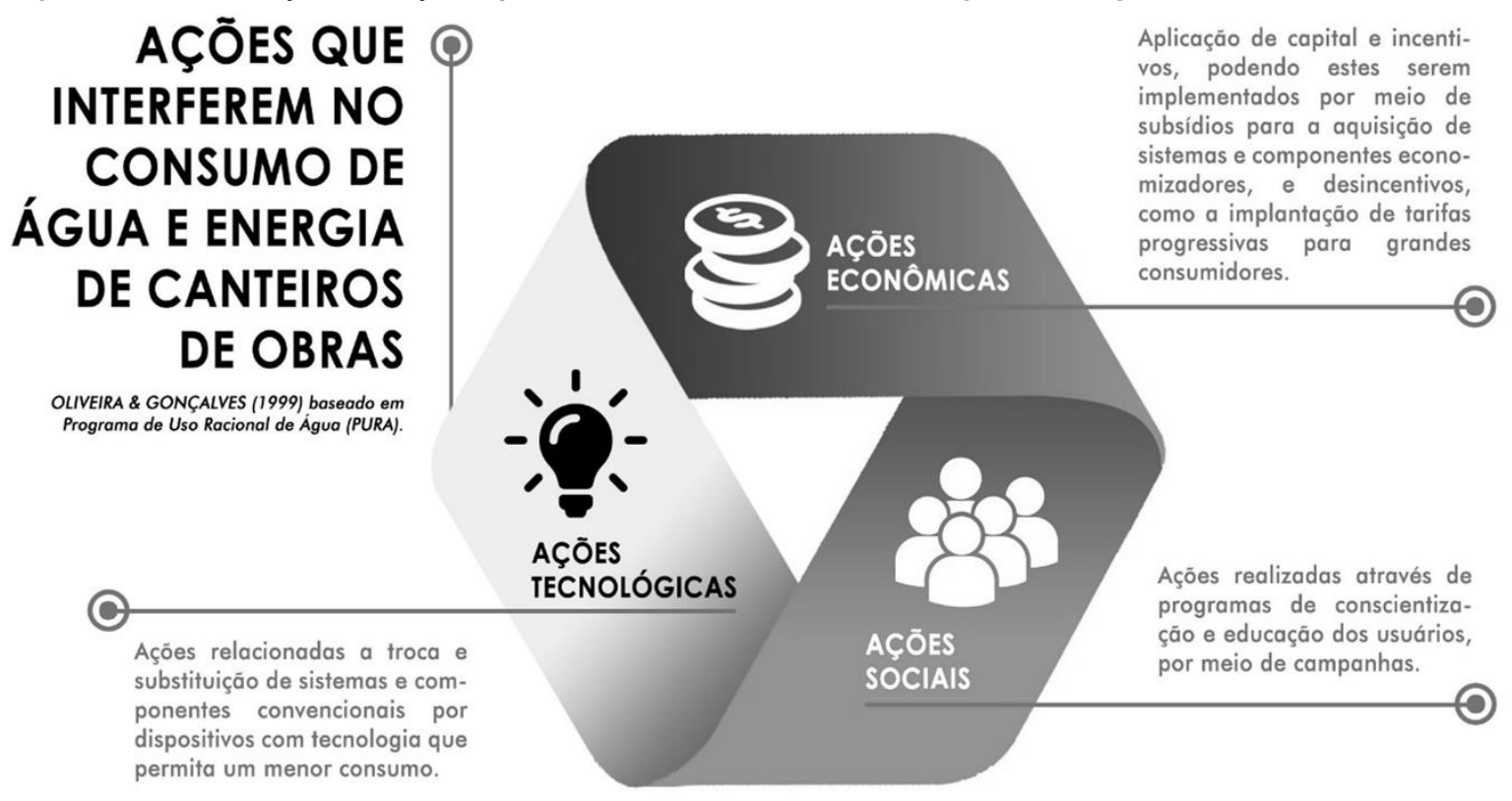

Fonte: adaptado de Oliveira e Gonçalves (1999). 
No que se refere ao consumo de água, a construção civil tem um grande potencial consumidor diretamente com materiais e processos como produção de concreto, supressão de poeira e corte, e indiretamente com a água incorporada em todos os produtos usados na construção -, apresentando elevado consumo de água para a execução das obras e fabricação de seus materiais (WATERWISE, 2017). Tais funções tornam o recurso hídrico um dos componentes mais importantes na execução de concretos e argamassas, e uma ferramenta eficaz nas atividades de limpeza e cura do concreto (SILVA; VIOLIN, 2013).

A água na indústria da construção é consumida na extração, produção e manufatura, bem como no processo de construção da edificação. As políticas têm focado apenas no uso de água operacional do ambiente construído, negligenciando o consumo em outras fases, uma vez que a água consumida para a execução das obras nos canteiros representa um percentual ínfimo se comparado ao total de água consumida ao longo da vida útil de uma edificação (MCCORMACK et al., 2007). A água consumida durante a manufatura de bens e serviços requeridos na construção pode ser significante no contexto do ciclo de vida de uma edificação. Existem, ainda, estudos como o de McCormack et al. (2007) que se concentram em mensurar o consumo de água incorporada na fase de construção das edificações. McCormack et al. (2007) realizaram 17 estudos de caso e encontraram um volume máximo de $20,1 \mathrm{~m}^{3} / \mathrm{m}^{2}$ de área construída. Esses mesmos autores salientam que, considerando a etapa construtiva dos edifícios, o volume de água requerida no processo principal de construção é mínimo. Também, Bardhan (2011) apresenta valores de consumo de água em canteiros de obra de $1 \mathrm{~m}^{3} / \mathrm{m}^{2}$ a $2 \mathrm{~m}^{3} / \mathrm{m}^{2}$ de área construída, ou seja, de $5 \%$ a $10 \%$ do valor total de água incorporada ao processo de construção de uma obra, considerando o ciclo de vida das matérias-primas e serviços inseridos. Por sua vez, Santos, Silva e Cerqueira (2015) encontraram um volume consumido de água de $0,83 \mathrm{~m}^{3} / \mathrm{m}^{2}$. Estes estudos revelam valores que variam em função das metodologias de levantamento utilizadas e dos contextos das obras.

A avaliação de consumo de água em canteiros de obra possibilita identificar possíveis falhas no sistema, como vazamentos, e até mesmo verificar padrões de consumo dos mais diversos processos, auxiliando, então, na busca, cada vez mais intensa, por soluções mais sustentáveis, que podem ser aplicadas em canteiros de obra durante a execução de empreendimentos (SINDICATO..., 2016).

\section{Método de pesquisa}

A estratégia de pesquisa empregada consiste no estudo de caso (YIN, 2015), tendo como objeto seis obras de edificações de uma construtora da cidade de Passo Fundo, RS.

\section{Caracterização do estudo de caso}

O estudo analisa uma construtora localizada na cidade de Passo Fundo atuante desde 1975 na construção civil, tendo executado mais de 60 prédios comerciais e residenciais, superando $250.000 \mathrm{~m}^{2}$ de área construída. A empresa é certificada pelo Programa Brasileiro de Qualidade e Produtividade no Habitat (PBQP-H), nível A, e pela norma ISO 9001, com um sistema de gestão da qualidade implementado há mais de dez anos.

Para o estudo foram selecionadas seis obras (Figura 2) executadas no período compreendido entre fevereiro de 2012 e outubro de 2016, únicas obras com os dados dos indicadores completos, com medições do início ao fim da execução.

Pelo fato de possuírem sistema de gestão da qualidade, as obras executadas pela empresa contam com uma série de controles em seus processos e serviços; por isso seus canteiros apresentaram certa regularidade na maneira com que são organizados, com padronização. Como as certificações que a empresa possui dizem respeito à gestão da qualidade, trazem como principal foco a qualidade do produto e a satisfação de seus clientes externos. Ao se acompanharem as obras da empresa para a coleta de dados, observou-se que as questões ambientais são relegadas a segundo plano, e, por mais que algumas das ações de controle já sejam realizadas pela empresa, estas não são eficazes para as questões ambientais, ficando restritas apenas ao atendimento de requisitos exigidos pelas normas de qualidade (BRASIL, 2012; ABNT, 2001).

\section{Levantamento dos dados}

O levantamento dos dados considerou:

(a) as medições de consumo de energia e água ao longo de todas as etapas de execução das seis obras, desde a data de início até a data de entrega das obras, totalizando um período de 5 anos de acompanhamento; e

(b) vistorias mensais ao longo do mesmo período de acompanhamento do indicador de consumo, com o objetivo de se diagnosticarem e identificarem os principais problemas existentes nos canteiros de obras que estariam influenciando o consumo de energia e água, ou alterando o comportamento dos indicadores. 
Figura 2 - Obras analisadas

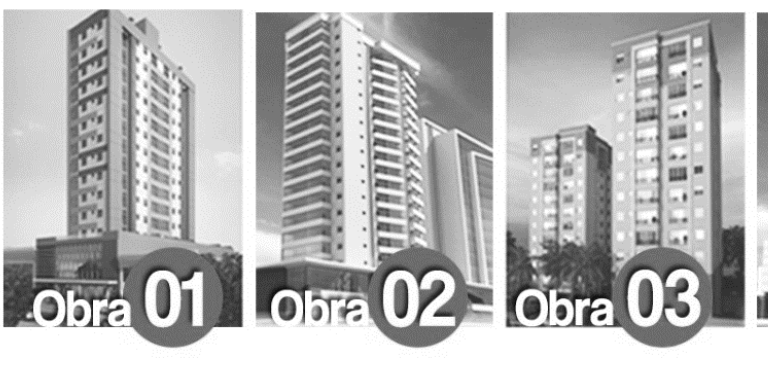

Uma das ações de controle realizadas pela empresa e que possui foco ambiental é o chamado indicador de sustentabilidade. Esse indicador tem por objetivo satisfazer o item 5.4.1.1 - Objetivos da qualidade voltados à sustentabilidade dos canteiros de obras da norma SiAC (BRASIL, 2012). Os indicadores são:

(a) indicador de consumo de água ao final da obra - consumo de água potável no canteiro de obra por metro quadrado de área construída - medido de modo acumulado ao final da obra em metro cúbico de água por metro quadrado de área construída; e

(b) indicador de consumo de energia ao final da obra - consumo de energia no canteiro de obra por metro quadrado de área construída - medido de modo acumulado ao final da obra em quilowatthora de energia elétrica por metro quadrado de área construída.

Os indicadores foram monitorados mensalmente a partir de medições realizadas in loco, sendo todo dia $1^{\circ}$ de cada mês anotados os valores obtidos nos medidores da obra (água e luz - fazendo-se a diferença com a medição do mês anterior, chegava-se ao do mês corrente). Com esse valor medido em obra, realizava-se a conferência com o valor da fatura da conta de energia e água fornecida pela concessionária. A meta desses indicadores, adotada pela empresa, considerou (Equação 1):

Meta para a Medição do mês seguinte < Média das útiams duas medições Eq. 1

\section{Analise dos dados}

A análise dos consumos de água e energia considerou as características índice de compacidade (IC), área construída, tipo de obra, tipos de materiais utilizados e técnicas construtivas.

A partir dos valores das áreas e dos perímetros das lajes dos pavimentos tipo das obras, foram calculados os índices de compacidade. Esse índice permite a percepção do quanto o projeto está próximo da forma mais econômica possível. Nesse indicador é comparado o perímetro externo do

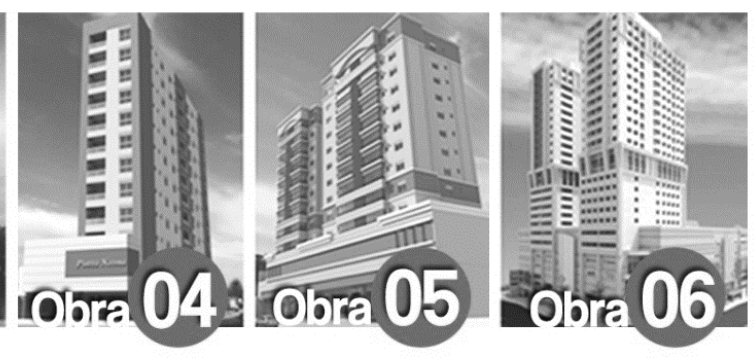

prédio ao perímetro de um círculo de mesma área. Assim, quanto mais próximo de $100 \%$, mais otimizada é a forma da planta baixa.

De acordo com Rocha (2014), a compacidade é tida como indicador de sustentabilidade tanto de edificações como de parcelas urbanas, sendo considerada fator determinante para a redução do consumo de material e, consequentemente, de energia incorporada dos processos construtivos, tendo também repercussão e importância macroeconômica. Esse índice é calculado pela Equação 2.

$I C=\frac{\sqrt{A p * \pi}}{P p}$

Onde:

$\mathrm{IC}=$ índice de compacidade;

Ap $=$ superfície do projeto $\left(\mathrm{m}^{2}\right) ; \mathrm{e}$

$\mathrm{Pp}=$ perímetro das paredes exteriores do projeto (m).

A proposição de ações visando à melhoria da sustentabilidade nos consumos observados nos canteiros foi classificada de acordo com a estrutura proposta por Oliveira e Gonçalves (1999), considerando problema observado, ação proposta e benefício potencial.

\section{Resultados e discussão}

As principais características das obras avaliadas no estudo são apresentadas na Tabela 1.

O cálculo do indicador para as obras do estudo permitiu identificar que os empreendimentos que apresentaram o maior índice de compacidade são do tipo comercial com valores de 0,84 nas obras 2 e 6, enquanto para as demais obras (residenciais) os índices apresentaram valores menores. Essas afirmativas propiciam as análises subsequentes em conjunto com indicadores de consumo.

\section{Análise dos indicadores de consumo}

A análise dos valores dos indicadores relativos ao consumo de água e energia é apresentada na Tabela 2 para as seis obras analisadas. 
Tabela 1 - Características das obras analisadas

\begin{tabular}{|c|c|c|c|c|c|c|c|c|c|c|c|}
\hline Obra & $\begin{array}{l}\text { Tipo } \\
\text { de } \\
\text { obra }\end{array}$ & $\begin{array}{c}\text { Sist. } \\
\text { Cons- } \\
\text { trutivo }\end{array}$ & $\begin{array}{l}\text { For- } \\
\text { mas }\end{array}$ & $\begin{array}{c}\text { Esco- } \\
\text { ramen- } \\
\text { tos }\end{array}$ & $\begin{array}{c}\mathbf{N}^{\circ} \\
\text { Pav. }\end{array}$ & $\mathbf{N}^{\circ}$ Und. & $\begin{array}{c}\text { Tipo } \\
\text { (1d, 2d, } \\
\text { kit, etc.) }\end{array}$ & $\begin{array}{l}\text { Área } \\
\text { laje } \\
\text { tipo } \\
\left(\mathbf{m}^{2}\right)\end{array}$ & $\begin{array}{c}\text { Perí- } \\
\text { metro } \\
\text { tipo } \\
(\mathbf{m})\end{array}$ & $\begin{array}{c}\text { Área } \\
\text { real } \\
\text { global } \\
\left(\mathbf{m}^{2}\right)\end{array}$ & $\begin{array}{c}\text { Índice } \\
\text { compa- } \\
\text { cidade } \\
\text { (IC) }\end{array}$ \\
\hline 01 & $\mathrm{R}$ & $\mathrm{CA}$ & $\mathrm{CB}$ & ME & 15 & 84 & $7 \mathrm{xKIT}$ & 283 & 91 & 6.224 & 0,66 \\
\hline \multirow{2}{*}{02} & $\mathrm{R}$ & \multirow{2}{*}{$\mathrm{CA}$} & MA & MA & 20 & 102 & 2x1D, 4xKIT & 275 & 95 & \multirow{2}{*}{15.969} & 0,76 \\
\hline & $\mathrm{C}$ & & $\mathrm{CB}$ & ME & 16 & 104 & 8 Salas & 420 & 95 & & 0,84 \\
\hline \multirow{2}{*}{03} & $\mathrm{R}$ & \multirow{2}{*}{$\mathrm{CA}$} & \multirow{2}{*}{ MA } & \multirow{2}{*}{$\mathrm{ME}$} & 14 & 52 & $3 \times 2 \mathrm{D}, 1 \times 3 \mathrm{D}$ & 315 & 75 & 13.705 & 0,80 \\
\hline & $\mathrm{R}$ & & & & 12 & 44 & $3 \times 2 \mathrm{D}, 1 \times 3 \mathrm{D}$ & 315 & 75 & 8.190 & 0,80 \\
\hline 04 & $\mathrm{R}$ & $\mathrm{CA}$ & MA & $\begin{array}{l}\text { MA/ } \\
\text { ME }\end{array}$ & 12 & 40 & $3 \times 2 \mathrm{D}, 1 \times 3 \mathrm{D}$ & 380 & 105 & 5.568 & 0,66 \\
\hline \multirow{2}{*}{05} & $\mathrm{R}$ & \multirow{2}{*}{$\mathrm{CA}$} & \multirow{2}{*}{ MA } & \multirow{2}{*}{ MA } & 12 & 27 & $3 \times \mathrm{KIT}$ & 120 & 50 & \multirow{2}{*}{5.046} & 0,78 \\
\hline & $\mathrm{R}$ & & & & 13 & 30 & $1 \times 1 D, 2 \times 2 D$ & 200 & 65 & & 0,77 \\
\hline 06 & $\mathrm{C}$ & $\mathrm{CA}$ & MA & MA & 21 & 169 & 9 Salas & 450 & 90 & 48870,8 & 0,84 \\
\hline
\end{tabular}

Nota: Legenda:

Tipo de obra: $\mathrm{R}=$ Residencial; $\mathrm{C}=$ Comercial;

Sistema construtivo: $C A$ = Concreto armado;

Formas: $\mathrm{CB}=$ Cubetas; $\mathrm{MA}=$ Madeira;

Escoramentos: $M E$ = Metálico; $M A$ = Madeira;

Revestimentos: $\mathrm{A}=$ Argamassado; $\mathrm{T}=$ Textura; $\mathrm{PA}=$ Pastilha; $\mathrm{PE}=$ Pele de vidro; $\mathrm{e}$

Tipo: $1 \mathrm{D}=1$ Dormitório; 2D = 2 Dormitórios; 3D = 3 Dormitórios; KIT = Quitinete.

Tabela 2 - Indicador consumo de energia $\left(\mathrm{kWh} / \mathrm{m}^{2}\right)$ e água $\left(\mathrm{m}^{3} / \mathrm{m}^{2}\right)$

\begin{tabular}{c|c|c|c|c|c|c}
\hline Obra & $\begin{array}{c}\text { Área } \\
\text { construída } \\
\left(\mathbf{m}^{2}\right)\end{array}$ & $\begin{array}{c}\text { Índice de } \\
\text { compaci- } \\
\text { dade }(\mathbf{I C})\end{array}$ & $\begin{array}{c}\text { Consumo } \\
\text { total de } \\
\mathbf{e n e r g i a} \\
\mathbf{( k W h )}\end{array}$ & $\begin{array}{c}\text { Indicador } \\
\left(\mathbf{k W h} / \mathbf{m}^{2}\right)\end{array}$ & $\begin{array}{c}\text { Consumo } \\
\text { total de água } \\
\left(\mathbf{m}^{\mathbf{3}}\right)\end{array}$ & $\begin{array}{c}\text { Indicador } \\
\left(\mathbf{m}^{\mathbf{3}} / \mathbf{m}^{\mathbf{2}}\right)\end{array}$ \\
\hline 1 & $6.223,66$ & 0,66 & $60.907,00$ & 9,79 & $1.721,22$ & 0,28 \\
2 & $15.969,04$ & $0,76 / 0,84$ & $4.302,51$ & 0,27 & 183,10 & 0,01 \\
3 & $13.704,93$ & $0,80 / 0,80$ & $97.500,00$ & 7,11 & $2.363,68$ & 0,17 \\
4 & $5.567,81$ & 0,66 & $55.266,00$ & 9,93 & $1.025,00$ & 0,18 \\
5 & $5.046,30$ & $0,78 / 0,77$ & $11.382,36$ & 2,26 & 655,20 & 0,13 \\
6 & $48.870,81$ & 0,84 & $39.679,22$ & 0,81 & 840,52 & 0,02 \\
\hline
\end{tabular}

Os valores obtidos revelam uma variação para o consumo de água entre $0,02 \mathrm{~m}^{3} / \mathrm{m}^{2}$ e $0,28 \mathrm{~m}^{3} / \mathrm{m}^{2}$ e indicam patamares de consumo inferiores aos encontrados em pesquisas já citadas na literatura (MCCORNACK et al., 2007; BARDHAN, 2011; SANTOS; SILVA; CERQUEIRA, 2015).

No indicador consumo de energia os valores encontraram-se entre $0,27 \mathrm{kWh} / \mathrm{m}^{2}$ e $9,93 \mathrm{kWh} / \mathrm{m}^{2}$ para as seis obras monitoradas.

As obras 2 e 6 apresentam valores inferiores às demais tanto para o consumo de água quanto para energia, como pode ser visualizado na Tabela 2 e na Figura 3.

As seis obras estudadas apresentam muitas particularidades que tornam os parâmetros calculados distintos. Dessa forma, é difícil se afirmar se esses indicadores obtidos são admissíveis, toleráveis ou não. Em obras com características repetitivas, a realidade é diferente, e os indicadores tornam-se mais representativos.
Os gráficos apresentados na Figura 3 permitem uma visualização em termos comparativos dos indicadores (valores médios) para as seis obras.

Os resultados obtidos para os indicadores de consumo de energia em $\mathrm{kWh}$ por área construída e consumo de água em volume por área construída para as seis obras analisadas (Tabela 2 e Figura 3) levam a algumas constatações:

(a) as duas obras com maior área construída (obras 2 e 6) apresentaram o menor consumo de energia e de água;

(b) as duas obras com menor consumo de energia e água (obras 2 e 6) são do tipo comercial; e

(c) as duas obras com maior IC (obras 2 e 6) apresentaram o menor consumo de energia e água, e vice-versa, ou seja, as duas obras com menor índice de compacidade apresentaram o maior consumo. 
Figura 3 - Gráficos indicadores de consumo de energia e água por área construída

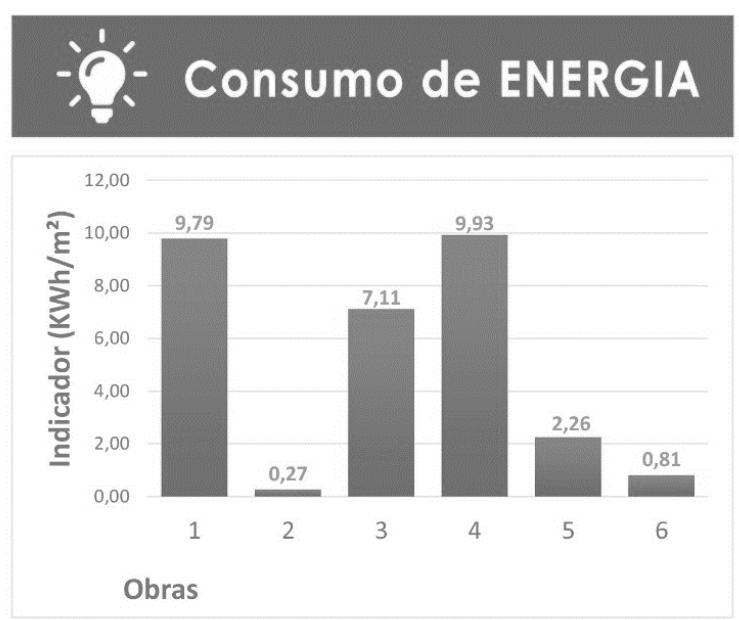

\section{Comportamento dos Indicadores Consumo de Energia e Água}

A partir das vistorias realizadas nas obras também foi possível a identificação de uma série de características e particularidades existentes entre elas. A avaliação dessas características juntamente com a análise dos indicadores de consumo leva a algumas considerações que podem explicar o comportamento dos indicadores para as obras em estudo.

\section{Técnicas construtivas}

Obras comerciais possuem características diferentes de obras residenciais no que diz respeito aos tipos de materiais utilizados e técnicas construtivas, sendo ambas mais racionalizadas e simplificadas, com menos acabamentos e revestimentos. Isso explicaria o comportamento em relação ao consumo de água e energia verificado para a obra 6 (comercial) e a obra 2 (comercial + residencial), com indicadores de consumos inferiores aos das demais obras pesquisadas.

Nestas obras foram observadas as seguintes diferenças com relação aos serviços executados:

(a) redução considerável na quantidade do serviço de cerâmicas em geral (porcelanatos e pastilhas devido a áreas menores de banheiros e cozinhas, e a inexistência de áreas de serviço);

(b) redução na quantidade do serviço de instalações hidrossanitárias e elétricas; e

(c) utilização de divisórias em gesso acartonado.

Com a redução na quantidade de execução dos serviços citados, tem-se menor consumo de água e energia, que estariam incorporados nos processos construtivos, bem como a redução na geração de

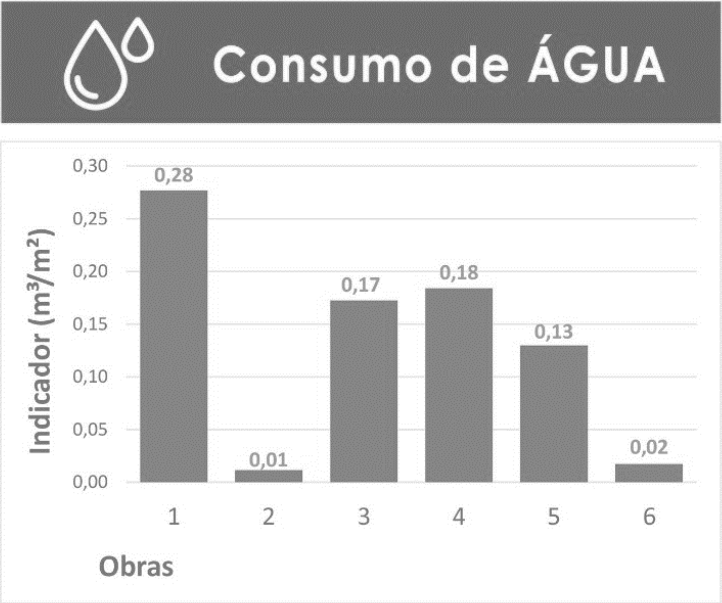

resíduos e a consequente necessidade de limpeza do canteiro de obra. Considerando uma análise do canteiro de obra, com a adoção das divisórias em gesso acartonado ocorre o mesmo, uma vez que esse serviço requer menos consumo de água e energia em sua instalação quando comparado a uma parede convencional, o que não pode ser verificado quando se analisa o ciclo de vida completo da produção de uma parede de gesso acartonado, incluindo todos os seus insumos e matérias-primas requeridos.

\section{Projeto}

Para as obras comerciais (obras 2 e 6) os projetos foram mais simplificados com relação ao partido arquitetônico, com menor perímetro e maior área nos pavimentos, o que explica o valor encontrado para o índice de compacidade (IC) nesses empreendimentos (Tabela 2), os maiores índices em comparação às demais obras.

Além disso, outras características destacam-se como relevantes: a estrutura (pilares, vigas e lajes) dessas obras foi concebida apresentando vãos maiores e espaços mais livres, representando uma área construída menor e, portanto, com consequente redução de consumo de água e energia incorporados ao concreto; para as divisórias internas houve considerável redução na compartimentação das unidades, com a execução de poucas paredes (ou nenhuma) de separação dos ambientes; para as fachadas foi adotada a execução de grandes aberturas com esquadrias e peles de vidro em substituição à vedação em alvenaria tradicional, que, para sua execução, exige maiores consumos de água e energia no canteiro de obra, não levando em consideração todo o ciclo de vida desses materiais. Essas características tornam o canteiro de obra uma linha de montagem, 
reduzindo a utilização de materiais e mitigando a geração de resíduos e o consumo de água e energia.

\section{Tamanho dos empreendimentos}

As obras do tipo comercial executadas pela empresa são consideravelmente maiores em valores de área construída quando comparadas às obras do tipo residencial, fazendo com que o tamanho dos espaços disponíveis para áreas de vivência fosse maior. Isso fez com que um número maior de pontos de iluminação e de água fosse instalado, o que gerou aumento no consumo de energia e água.

O tamanho do empreendimento também influencia no valor do indicador de consumo, uma vez que este é calculado mediante a divisão do valor consumo pela área construída. Sendo assim, obras maiores levam à diluição do consumo real medido, ocasionando diminuição do indicador final.

Por outro lado, obras maiores requerem maior controle sob seus processos por terem um número superior de atividades ocorrendo ao mesmo tempo, bem como maior número de colaboradores. Sendo assim, as obras 2 e 6 seguidamente apresentavam problemas de organização e limpeza do canteiro de obra, fato que talvez explique a menor utilização de água para limpeza do canteiro e o consequente menor consumo de água.

\section{Ações propostas}

As vistorias realizadas nas obras não só forneceram subsídios para o conhecimento das características técnicas e construtivas discutidas na análise dos indicadores, como também propiciaram o levantamento dos principais problemas relacionados ao consumo de água e energia dentro dos canteiros de obras. A partir destes problemas e da classificação proposta por Oliveira e Gonçalves (1999) foram definidas ações que podem ser incorporadas pela empresa ou outras organizações que executam empreendimentos similares para a redução do consumo e desperdício de energia e água nos canteiros de obra. O Quadro 1 apresenta essas ações juntamente com seus efeitos e benefícios.

Quadro 1 - Ações propostas para redução do consumo de energia e água (Continua...)

\begin{tabular}{|c|c|c|c|c|}
\hline \multirow{5}{*}{ 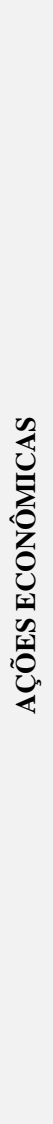 } & PROBLEMAS & AÇÕES & EFEITOS & BENEFÍCIOS \\
\hline & $\begin{array}{l}\text { Etapas de projeto com } \\
\text { problemas de } \\
\text { comunicação entre as } \\
\text { partes envolvidas. }\end{array}$ & $\begin{array}{l}\text { Promover reuniões periódicas para a } \\
\text { realização de tomadas de decisão, } \\
\text { integrando as equipes do projeto } \\
\text { arquitetônico com as equipes dos } \\
\text { projetos complementares. }\end{array}$ & $\begin{array}{l}\text { Reduzir a relação área de } \\
\text { fachada-área construída, } \\
\text { usar sistemas construtivos } \\
\text { industrializados, reduzir } \\
\text { elementos que consomem } \\
\text { energia e água para sua } \\
\text { execução no canteiro de } \\
\text { obra. }\end{array}$ & $\begin{array}{l}\text { Otimizar e reduzir } \\
\text { desperdícios de água, } \\
\text { energia e materiais. }\end{array}$ \\
\hline & $\begin{array}{l}\text { Restrições por parte } \\
\text { da direção na } \\
\text { liberação de verbas } \\
\text { para a realização de } \\
\text { algumas ações de } \\
\text { melhorias no sistema } \\
\text { de gestão. }\end{array}$ & $\begin{array}{l}\text { Incentivo financeiro por parte da direção } \\
\text { da empresa para a realização de } \\
\text { melhorias para o funcionamento } \\
\text { eficiente de todos os sistemas, bem } \\
\text { como planejamento, controle e gestão } \\
\text { dos canteiros de obra. }\end{array}$ & $\begin{array}{l}\text { Assegurar os investimentos } \\
\text { necessários para } \\
\text { manutenção do } \\
\text { gerenciamento das ações } \\
\text { de controle de consumo de } \\
\text { energia e água nos } \\
\text { canteiros de obra. }\end{array}$ & $\begin{array}{l}\text { Reduzir desperdícios de } \\
\text { água, energia e materiais, } \\
\text { bem como a geração de } \\
\text { resíduos da construção } \\
\text { civil. }\end{array}$ \\
\hline & $\begin{array}{l}\text { Utilização de } \\
\text { equipamentos sem } \\
\text { manutenção, levando } \\
\text { ao uso inadequado e } \\
\text { consequente maior } \\
\text { consumo de energia } \\
\text { devido à sobrecarga } \\
\text { de tarefas para o } \\
\text { profissional } \\
\text { responsável pelas } \\
\text { manutenções } \\
\text { preventivas. }\end{array}$ & $\begin{array}{l}\text { Disponibilização de mão de obra } \\
\text { exclusiva para realização de adequadas e } \\
\text { efetivas manutenções preventivas e } \\
\text { corretivas dos equipamentos, } \\
\text { observando suas especificações quando } \\
\text { da necessidade de substituição de } \\
\text { peças/componentes. }\end{array}$ & $\begin{array}{l}\text { Garantir que todos os } \\
\text { equipamentos sejam } \\
\text { utilizados de maneira } \\
\text { adequada e de acordo com } \\
\text { as especificações de uso do } \\
\text { fabricante, aumentando sua } \\
\text { eficiência e durabilidade, } \\
\text { evitando riscos de } \\
\text { acidentes e reduzindo } \\
\text { consumo de energia. }\end{array}$ & $\begin{array}{l}\text { Reduzir o consumo de } \\
\text { energia por equipamentos } \\
\text { avariados. }\end{array}$ \\
\hline & $\begin{array}{l}\text { Inexistência de } \\
\text { inspeções acerca das } \\
\text { instalações provisórias } \\
\text { e tubulações das áreas } \\
\text { de vivência do } \\
\text { canteiro de obras. }\end{array}$ & $\begin{array}{l}\text { Disponibilização de mão de obra } \\
\text { exclusiva para realização de inspeções } \\
\text { periódicas nas instalações provisórias na } \\
\text { busca de possíveis vazamentos no } \\
\text { canteiro de obra. }\end{array}$ & $\begin{array}{l}\text { Garantir que não ocorram } \\
\text { vazamentos nos canteiros } \\
\text { de obra e, caso ocorram, } \\
\text { que eles sejam } \\
\text { identificados rapidamente } \\
\text { para maior agilidade em } \\
\text { sua resolução. }\end{array}$ & $\begin{array}{l}\text { Reduzir o consumo de } \\
\text { água decorrente a } \\
\text { vazamentos. }\end{array}$ \\
\hline
\end{tabular}

86 Marques, C. T.; Gomes, B. M. F.; Brandli, L. L. 


\section{Quadro 1 - Ações propostas para redução do consumo de energia e água (continuação)}

\begin{tabular}{|c|c|c|c|c|}
\hline 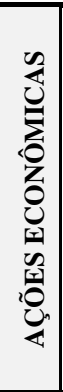 & $\begin{array}{l}\text { No momento da } \\
\text { compra não é levada } \\
\text { em consideração a } \\
\text { eficiência dos } \\
\text { equipamentos, } \\
\text { máquinas e } \\
\text { eletrodomésticos para } \\
\text { as instalações } \\
\text { provisórias das obras, } \\
\text { sendo considerados } \\
\text { apenas os custos de } \\
\text { sua aquisição. }\end{array}$ & $\begin{array}{l}\text { Utilização de equipamentos e máquinas } \\
\text { certificados pelo Programa Brasileiro de } \\
\text { Etiquetagem do Inmetro, possuir o selo } \\
\text { Procel ou Conpet nível A, considerando } \\
\text { a especificidade e a necessidade de cada } \\
\text { item (equipamentos utilizados na } \\
\text { execução do empreendimento, como } \\
\text { serras manuais, rompedores, etc.; } \\
\text { também, eletrodomésticos utilizados no } \\
\text { refeitório, almoxarifado, vestiários, etc.). }\end{array}$ & $\begin{array}{l}\text { Garantir que apenas sejam } \\
\text { adquiridos e utilizados } \\
\text { equipamentos com } \\
\text { qualidade comprovada e } \\
\text { reconhecida, e com } \\
\text { certificação de eficiência } \\
\text { energética. }\end{array}$ & $\begin{array}{l}\text { Reduzir o consumo de } \\
\text { energia. }\end{array}$ \\
\hline \multirow{4}{*}{ 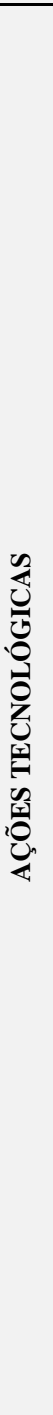 } & $\begin{array}{l}\text { Utilização de } \\
\text { lâmpadas de baixa } \\
\text { qualidade nas áreas de } \\
\text { vivências das obras. }\end{array}$ & $\begin{array}{l}\text { Utilização de lâmpadas fluorescentes } \\
\text { compactas e/ou lâmpadas de LED para } \\
\text { as áreas de uso comum e vivência do } \\
\text { canteiro de obra. }\end{array}$ & $\begin{array}{l}\text { Aumentar a eficiência dos } \\
\text { sistemas de abastecimento } \\
\text { de energia (circuitos e } \\
\text { pontos de iluminação). }\end{array}$ & $\begin{array}{l}\text { Reduzir o consumo de } \\
\text { energia e geração de } \\
\text { resíduos perigosos } \\
\text { (lâmpadas fluorescentes). }\end{array}$ \\
\hline & $\begin{array}{l}\text { Fabricação de } \\
\text { argamassa para } \\
\text { revestimentos em } \\
\text { obra; também de } \\
\text { concreto em algumas } \\
\text { situações específicas. }\end{array}$ & $\begin{array}{l}\text { Utilização de concreto e argamassa } \\
\text { fabricados por empresas terceirizadas } \\
\text { especializadas em vez de fabricação in } \\
\text { loco, nas obras. }\end{array}$ & $\begin{array}{l}\text { Evitar problemas oriundos } \\
\text { da incorreta dosagem e } \\
\text { produção da argamassa e } \\
\text { do concreto (problemas de } \\
\text { resistência do concreto, } \\
\text { problemas com aderência } \\
\text { de revestimentos, entre } \\
\text { outros). }\end{array}$ & $\begin{array}{l}\text { Mitigar o consumo de } \\
\text { água e de materiais para } \\
\text { a fabricação de concreto } \\
\text { e argamassa. }\end{array}$ \\
\hline & $\begin{array}{l}\text { Utilização de torneiras } \\
\text { de baixa qualidade. } \\
\text { Utilização de bacias } \\
\text { sanitárias com sistema } \\
\text { de descarga comum. }\end{array}$ & $\begin{array}{l}\text { Implantação de tecnologias } \\
\text { economizadoras em pontos de uso, } \\
\text { como as torneiras dos banheiros e } \\
\text { refeitório. } \\
\text { Emprego de bacias sanitárias com } \\
\text { sistema duplo de descarga nos banheiros } \\
\text { das obras. }\end{array}$ & $\begin{array}{l}\text { Diminuir a ocorrência de } \\
\text { problemas pela utilização } \\
\text { de materiais de baixa } \\
\text { qualidade e aumentar a } \\
\text { eficiência dos sistemas de } \\
\text { abastecimento de água } \\
\text { (tubulações e pontos de } \\
\text { consumo). }\end{array}$ & $\begin{array}{l}\text { Reduzir o consumo de } \\
\text { água. }\end{array}$ \\
\hline & $\begin{array}{l}\text { Não é realizada a } \\
\text { captação de água da } \\
\text { chuva para } \\
\text { reaproveitamento em } \\
\text { obra. }\end{array}$ & $\begin{array}{l}\text { Utilização de águas pluviais como fonte } \\
\text { de água alternativa para limpeza do } \\
\text { canteiro de obra e demais finalidades } \\
\text { não potáveis. }\end{array}$ & $\begin{array}{l}\text { Reduzir o consumo de } \\
\text { água fornecida pela } \\
\text { concessionária e } \\
\text { consequentemente reduzir } \\
\text { os gastos com tarifas. }\end{array}$ & $\begin{array}{l}\text { Reduzir o consumo de } \\
\text { água e recursos } \\
\text { financeiros. }\end{array}$ \\
\hline 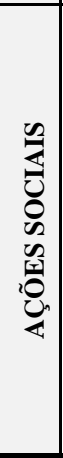 & $\begin{array}{l}\text { São realizados } \\
\text { treinamentos apenas } \\
\text { com relação à } \\
\text { segurança do trabalho, } \\
\text { normas da empresa e } \\
\text { instruções de trabalho, } \\
\text { sem considerar as } \\
\text { questões de } \\
\text { conscientização } \\
\text { ambiental dos } \\
\text { colaboradores em } \\
\text { relação ao consumo de } \\
\text { recursos dentro dos } \\
\text { canteiros de obra. }\end{array}$ & $\begin{array}{l}\text { Realização de campanhas para que os } \\
\text { trabalhadores sejam sensibilizados e } \\
\text { envolvidos em ações de conscientização } \\
\text { para o uso racional de energia. } \\
\text { Realização de capacitações contínuas e } \\
\text { eficazes para fins de sensibilização e } \\
\text { desenvolvimento de estratégias que } \\
\text { contemplem o planejamento de redução } \\
\text { de consumo de água no canteiro de obra. }\end{array}$ & $\begin{array}{l}\text { Desenvolvimento pessoal } \\
\text { dos colaboradores devido à } \\
\text { maior capacitação com } \\
\text { relação às questões de } \\
\text { consumo de energia e } \\
\text { água, tornando-os mais } \\
\text { conscientes da importância } \\
\text { de suas ações dentro do } \\
\text { local de trabalho, } \\
\text { engajados e preocupados } \\
\text { com o uso racional dos } \\
\text { recursos. }\end{array}$ & $\begin{array}{l}\text { Evitar o desperdício de } \\
\text { energia, de água, etc., } \\
\text { dentro do canteiro de } \\
\text { obra. } \\
\text { Reduzir o consumo de } \\
\text { água e potencializar } \\
\text { planejamento de redução } \\
\text { de consumo de insumos e } \\
\text { materiais. }\end{array}$ \\
\hline
\end{tabular}


Além das ações propostas acima, que podem ser aplicadas em todas as obras da empresa estudada, independentemente do tipo de uso e ocupação delas, outras ações podem ser listadas especificamente para as obras do tipo residencial, como apropriar-se das soluções utilizadas nas obras comerciais a fim de reduzir o consumo de água e energia nelas, como adoção de solução arquitetônica com maior índice de compacidade sem comprometer outros fatores, como iluminação natural e ventilação natural; redução da compartimentação e substituição de paredes de alvenaria por sistemas semi-industrializados, como o gesso acartonado, considerando que os insumos e matérias-primas incorporados não maximizam o consumo de água e energia; e adoção de sistemas construtivos que levem à redução de resíduos e do consumo de energia e água.

\section{Conclusão}

Este artigo apresentou um levantamento em seis obras ao longo de todo o seu processo de execução (canteiro de obra) do consumo de energia e consumo de água. Os resultados mostraram que há variação nos consumos em função da gestão da obra e de suas características, como tipo de obra, técnicas construtivas, índice de compacidade (IC) e área construída.

A avaliação dos consumos de água e energia em canteiros de obra possibilita um tratamento do uso desses recursos com maior eficiência, de forma que a empresa, além de monitorar seu desempenho, possa identificar possíveis falhas nos sistemas e principalmente possibilidades de otimização deles.

Em termos de consumo de água, os resultados mostraram uma variação entre $0,02 \mathrm{~m}^{3} / \mathrm{m}^{2}$ e 0,28 $\mathrm{m}^{3} / \mathrm{m}^{2}$, e o consumo de energia entre $0,27 \mathrm{kWh} / \mathrm{m}^{2}$ e $9,93 \mathrm{kWh} / \mathrm{m}^{2}$ para as seis obras monitoradas.

As falhas identificadas ao longo do acompanhamento das obras se referiram a aspectos relacionados ao processo de decisão na etapa de projeto, compras e execução, e podem ser reduzidas ou mesmo eliminadas, na maioria das vezes, com ações simples e coordenadas.

Todas as ações propostas foram baseadas neste estudo de caso, mas certamente, com vistas a reduzir o consumo e desperdício de energia e água nos canteiros de obra, podem ser incorporadas por outras organizações que executam empreendimentos com características semelhantes: habitacionais e comerciais com estrutura convencional em concreto armado.

Um aspecto importante é o comprometimento da direção da empresa com a eficiência no uso dos recursos na obra. Este é o ponto inicial e talvez crucial para a implementação de ações de melhoria, uma vez que estas envolvem investimentos, desde um projeto racional, uso de tecnologias e materiais economizadores, alocação da mão de obra para manutenção e inspeção, e desenvolvimento dos colaboradores.

\section{Referências}

\author{
AGOPYAN, V. et al. Alternativas Para a \\ Redução do Desperdício de Materiais nos \\ Canteiros de Obras. São Paulo: Finep; ITQC; \\ PCC-USP, 1998.
}
AJAYI, S. O. et al. Optimising Material
Procurement for Construction Waste
Minimization: an exploration of success factors.
Sustainable Materials and Technologies, v. 11, p. 38-46, 2017.

ARAÚJO, V. M. Práticas Recomendadas Para a Gestão Mais Sustentável de Canteiro de Obras. São Paulo, 2009. Dissertação (Mestrado em Engenharia) - Escola Politécnica, Universidade de São Paulo, São Paulo, 2009.

\begin{abstract}
ASSOCIAÇÃO BRASILEIRA DE NORMAS TÉCNICAS. NBR ISO 9001/2000: sistemas de gestão da qualidade. Rio de Janeiro, 2001.
\end{abstract}

BALTAR, G. B.; KAEHLER, J. W. M.; PEREIRA, L. A. Indústria da Construção Civil e Eficiência Energética. 2006. Disponível em: <http://repositorio.pucrs.br/dspace/bitstream/1092 3/3210/5/000384715

Texto\%2BCompleto\%2BAnexo\%2BE-5.pdf>. Acesso em: 2 mar. 2017.

BARDHAN, S. Assessment of Water Resource Consumption in Building Construction in India. Ecosystems and Sustainable Development VIII, V. 144, p. 93-102, 2011.

BRASIL. Sistema de Avaliação da Conformidade de Empresas de Serviços e Obras da Construção Civil - SiAC. 2012. Disponível em <http://pbqp-

h.cidades.gov.br/download.php?doc=fb9ee53656b0-4cf1-a6d0-

eade79e84f81\&ext=.pdf\&cd=2435>. Acesso em: 16 out. 2016 .

CARDOSO, F. F.; ARAUJO, V. M. Redução de Impactos Ambientais do Canteiro de Obras. In: PROJETO para Construção Habitacional Mais Sustentável. São Paulo: Edusp, 2004.

CARDOSO, F. F.; ARAUJO, V. M. Canteiros de Obras. In: PROJETO Tecnologias para Construção Habitacional Mais Sustentável: estado da arte. São Paulo: Edusp, 2006. 
CRAWFORD, R.; TREOLOAR, G. An Assessment of the Energy and Water Embodied in Commercial Building Construction. In: AUSTRALIAN LIFE CYCLE ASSESSMENT CONFERENCE, 4., Sydney, 2005. Proceedings... Sydney, 2005.

DIAS, F. S. Etapas e Procedimentos nos Canteiros de Obras e Suas Influências no Desperdício na Construção Civil. Campo dos Goitacazes, 2006. Dissertação (Mestrado em Engenharia Civil) - Universidade Estadual do Norte Fluminense, Campo dos Goitacazes, 2006.

FARIAS, P. M. A. Construção Sustentável: contributo para o processo de construção na alteração de uso nos Edifícios. Lisboa, 2010. Dissertação (Mestrado em Engenharia Civil) Faculdade de Ciências e Tecnologia, Universidade Nova de Lisboa, Lisboa, 2010.

LOPES, J.; OLIVEIRA, R.; ABREU, M. I. The Sustainability of the Construction Industry in SubSaharan Africa: some new evidence from recent data. Procedia Engeneering, v. 172, p. 657-664, 2017.

MACHADO, F. M. Gestão Sustentável: o gerenciamento dos resíduos sólidos da construção civil. Rio de Janeiro, 2006. Dissertação (Mestrado de Engenharia Civil) - Escola de Engenharia, Universidade Federal Fluminense, Rio de Janeiro, 2006.

MCCORMACK, M. et al. Modelling Direct and Indirect Water Requirements of Construction.

Building Research \& Information, v. 35, n. 2, p. 156-162, 2007.

MINISTÉRIO DO MEIO AMBIENTE.

Construção Sustentável. Disponível em:

<http://www.fee.rs.gov.br/perfil-

socioeconomico/municipios/>. Acesso em: 7 maio 2017.

OLIVEIRA, L. H.; GONÇALVES, O. M. Metodologia Para a Implantação de Programa de Uso Racional de Água em Edifícios. São Paulo, 1999. Boletim Técnico PCC/247.

ORGANIZAÇÃO DAS NAÇÕES UNIDAS. Governo Brasileiro e PNUD Publicam Vídeos Didáticos Sobre Eficiência Energética na Construção Civil. 2016. Disponível em: $<$ https://nacoesunidas.org/governo-brasileiro-epnud-publicam-videos-didaticos-sobre-eficienciaenergetica-na-construcao-civil/>. Acesso em: 2 mar. 2017.
ROCHA, S. J. J. Compacidade Urbana e

Arquitetônica Como Indicador de

Sustentabilidade. In: CONGRESSO

INTERNACIONAL SUSTENTABILIDADE E

HABITAÇÃO DE INTERESSE SOCIAL, Porto Alegre, 2014. Anais... Porto Alegre: EDIPUCRS, 2014.

SALGADO, M. S.; CHATELET, A.; FERNANDEZ, P. Produção de Edificações Sustentáveis: desafios e alternativas. Ambiente Construído, Porto Alegre, v. 12, n. 4, p. 81-99, out./dez. 2012.

SANTOS, C. P.; SILVA, S. R.; CERQUEIRA, C. A. Water Consumption in Construction Sites in the City of Recife/PE. Electronic Journal of Geotechnical Engineering, v. 20, n. 7, p. 17111726, 2015 .

SHARRARD, A. L.; MATTHEWS, S.; ROTH, M. Environmental Implications of Construction Site Energy Use and Electricity Generation. Journal of Construction Engineering and Management, p. 846-854, 2007.

SILVA, R. R.; VIOLIN, R. Y. T. Gestão da Água em Canteiros de Obras de Construção Civil. In: ENCONTRO INTERNACIONAL DE PRODUÇÃO CIENTÍFICA, 7., Maringá, 2013. Maringá. Anais... Maringá: EPCC, 2013.

SINDICATO DA INDÚSTRIA DA CONSTRUÇÃO E MOBILIÁRIO DO RIO GRANDE DO SUL. Guia de Sustentabilidade na Construção Civil no Rio Grande do Sul.

Disponível em: <http://www.sindusconrs.com.br/wpcontent/uploads/2013/06/Cartilha_Sustentabilidade _WEB.pdf $>$. Acesso em: 2 set. 2016.

SOBOTKA, A.; SAGAN, J. Cost-Saving Environmental Activities on Construction Site: cost efficiency of waste management: case study. Procedia Engeneering, v. 161, p. 388-393, 2016.

SOUZA, U. E. L. Projeto e Implantação do Canteiro. São Paulo: O Nome da Rosa, 2000.

TAVARES, D. A. C. Gestão Pública de Resíduos Sólidos da Construção Civil em Aracajú: um desafio ambiental. Sergipe, 2007. Dissertação (Mestrado em Desenvolvimento e Meio Ambiente) - Núcleo de Pós-Graduação em Desenvolvimento e Meio Ambiente, Universidade Federal de Sergipe, Sergipe, 2007.

UNITED NATIONS. The Millennium

Development Goals Report. 2015.

WATERWISE. International Water Association Efficient. 2017. Disponível em:

<http://www.waterwise.org.uk>. Acesso em: 2 mar. 2017. 
YIN, R. Estudo de Caso: planejamento e métodos. 5. ed. Porto Alegre: Bookman, 2015.

\section{Cristian Teixeira Marques}

Mestrando do Programa de Pós-graduação em Engenharia Civil e Ambiental, Faculdade de Engenharia e Arquitetura | Universidade de Passo Fundo | Bolsa Construções e Incorporações | Passo Fundo - RS - Brasil | Rua Independência, 800, Conj. 701, Centro | CEP $99010-041$ | Tel.: (54) 3311-3400 | E-mail: cristian.marques@hotmail.com

\section{Bárbara Maria Fritzen Gomes}

Mestranda do Programa de Pós-graduação em Engenharia Civil e Ambiental, Faculdade de Engenharia e Arquitetura | Universidade de Passo Fundo | Campus 1, Km 171, BR 285, São José | Passo Fundo - RS - Brasil | Caixa Postal 611 | CEP 99001-970 | Tel.: (54) 3316-8283 | E-mail: barbara.m.fritzen@gmail.com

\section{Luciana Londero Brandli}

Professora do Programa de Pós-Graduação em Engenharia Civil e Ambiental, Faculdade de Engenharia e Arquitetura | Universidade de Passo Fundo | Tel.: (54) 3316-8100 Ramal 8203 | E-mail: brandli@upf.br

\section{Revista Ambiente Construído}

Associação Nacional de Tecnologia do Ambiente Construído

Av. Osvaldo Aranha, $99-3^{\circ}$ andar, Centro

Porto Alegre - RS - Brasil

CEP $90035-190$

Telefone: +55 (51) 3308-4084

Fax: +55 (51) 3308-4054

www.seer.ufrgs.br/ambienteconstruido

E-mail: ambienteconstruido@ufrgs.br

90 Marques, C. T.; Gomes, B. M. F.; Brandli, L. L. 